\title{
Banking Finance Experts Consensus on Compliance in US Bank Holding Companies: An e-Delphi Study
}

\author{
Sophia Velez ${ }^{1, *,+} \mathbb{1}$, Michael Neubert $^{2}$ and Daphne Halkias ${ }^{2}$ \\ 1 College of Management and Technology, School of Management, Walden University, 100 Washington \\ Avenue South, Suite 900, Minneapolis, MN 55401, USA \\ 2 School of Management, International School of Management Paris, 17 Boulevard Raspail, \\ 75007 Paris, France; michael.neubert@mail.waldenu.edu (M.N.); daphne.halkias@mail.waldenu.edu (D.H.) \\ * Correspondence: sophia.velez@waldenu.edu \\ + Sophia Velez has worked over 16 years as a Certified Public Accountant (CPA) with large banks providing \\ consulting services. As a CPA, she worked for firms such as PriceWaterhoCoopers LLP (PwC) where she \\ performed financial audits and attestation services for large banks.
}

Received: 30 December 2019; Accepted: 29 January 2020; Published: 5 February 2020

\begin{abstract}
Compliance measures emphasized in the Dodd-Frank Bill 2010, Section 165 is a response to the 2008 financial crisis, that requires large banks to maintain a minimum capital ratio. The Federal Reserve Bank (Fed) regulates capital of Bank Holding Companies (BHC) through compliance Supervisory Capital Assessment Program (SCAP) 2009 and Comprehensive Capital Adequacy Review (CCAR) 2011 annual stress test of capital. The Fed imposed a minimum capital ratio of $8 \%$ that has derailed the risk management objective of capital adequacy, as bank managers are forced to take on more risk to meet the capital ratio. This study concerns senior manager practices that can be effective in meeting compliance requirements posed by the Fed for BHCs. Through a qualitative e-Delphi study, 10 banking finance experts were convened to build consensus on senior manager's practices that can be effective in meeting compliance requirements. Data were collected from three electronic questionnaires submitted through Qualtrics. Data were analyzed using theoretical triangulation, coding, and thematic analysis. Four important considerations were identified that could bolster compliance measures effectiveness: (a) emphasis placed on understanding regulatory consultant compliance, (b) maintenance of effective and independent compliance align to organizational objectives, (c) clear definition of data source for compliance analytics. These considerations of compliance practices may help senior bank managers reduce risky behaviors and investments that cause significant bank losses.
\end{abstract}

Keywords: BHC; compliance; capital regulation; risk management; compliance analytics

\section{Introduction and Background}

An examination of six significant USA Bank Holding Companies' capital and losses revealed that their operational risk exposure is higher today than it was prior to the 2008 recession, which exposes them to insolvency (Sarin and Summers 2016). Large banks are significant financial institutions (SIFI) and when they sustain significant losses without adequate capital, they can become insolvent and pose a systemic risk to the U.S. economy (Berger et al. 2018; Crawford 2017; Gong et al. 2018). The 2008 recession in the U.S. resulted in the banking sector being in a disastrous state and financial crisis (Rahman 2012). The government responded to the crisis by offering bailouts to hundreds of banks and passing the broadest set of regulatory reforms since the 1930s (Guynn 2010). Government regulatory reforms such as the Dodd-Frank Bill 2010, Section 165. gave powers to the Federal Reserve Bank (Fed) to enforced compliance measures that regulate the capital of BHC (Tanda 2015). Compliance 
measures require large banks $\$ 50$ billion or more in assets to conduct an annual stress test and file a capital plan, proposing how much dividends they plan to pay out over the next nine quarters (Fahey 2016). Fed requires large banks to perform Supervisory Capital Assessment Program (SCAP) 2009 and Comprehensive Capital Adequacy Review (CCAR) 2011 annual stress test of capital.

Compliance requirements in Section 165 require banks: (1) maintains a minimum amount of contingent capital that is convertible to equity in times of financial stress... (2) enhanced public disclosures ... (3) short-term debt limits, including off-balance sheet exposures ... (4) a catchall provision allowing "such other prudential standards as the Board of Governors (Wan 2016, pp. B12-B13). These types of prudential regulations prevent bank defaults through the enforcement of compliance rules that require the maintenance of sufficient capital to cover losses (Tanda 2015). The Fed requires BHC to maintain a minimum net capital ratio percentage of 8 percent (Tanda 2015). BHCs experienced low level of leverage, liquidity, capital, and risky senior bank manager behavior. They have significantly higher debt to equity ratios, held lower liquidity and capital adequacy ratios, engaged in greater home mortgage lending, and had a higher proportion of defaulting first and second (junior) home mortgages than unaffiliated banks (Dandapani et al. 2017).

Despite the new compliance requirements, the Fed imposed a required capital ratio of 8 percent has derailed the risk management objective of capital adequacy, as bank managers are forced to take on more risk to meet capital ratio and meet shareholder's profit expectations. Risky management behavior is incentivized by goal theory, the motives and incentives embedded in goal theory are significant to garner commitment to the goal by the individual (Sepdiningtyas and Santoso 2017). These intrinsic and extrinsic motivations embedded in goal theory may be tied to unclear goals established by principals to motivate their agents, which may lead to dysfunctional behavioral responses on the part of agents (Osterloh and Frey 2000). These unanticipated losses in megabanks and the continuance of economic turmoil suggest the ineffective delivery of capital regulation (Tanda 2015; Yeoh 2016).

The main motivation for this study is to determine what is the level of consensus among banking finance experts across the United States on how to recognize effective compliance practice towards capital regulation in BHCs? These practices towards compliance can assist senior managers to meet the Fed requirements while minimizing risky behaviors that lead to losses. The need for effective capital regulation practices has been documented as a necessary requirement to reduce agency theory risk exposure evident in abusive high-frequency trading practices (Barr 2017). As Tanda (2015) noted, compliance requirements that regulate capital have failed to reduce losses and operational risk in BHCs as enacted through Dodd-Frank Bill 2010, Section 165. The problem is large banks lack practices that can be effective towards compliance measures that can reduce significant losses and risk management behavior. The increase of risk incurred by banks while meeting compliance requirements can be prevented in a respectable risk culture that informs all financial risk-taking and managerial decisions (Eastburn and Sharland 2017).

To solve this problem, an e-Delphi study is employed to build consensus among 10 banking finance experts across the United States on how to identify effective compliance practices towards capital regulation in banks that can reduce significant losses and risk management behavior. Delphi method explores an area of future thinking that goes beyond the currently known or believed (Hsu and Sandford 2007). This technique gathers expert predictions under the guidance of a facilitator who controls these forecasts until group consensus is established (Ibiyemi et al. 2016). Three rounds of questionnaires are submitted to panelist through online platform, the first-round questionnaire was an open-ended approach to gather expert opinions on a certain issue, the second questionnaire asks the panel of experts to rank these statements, and third, the group reach consensus (Cole et al. 2013; Donohoe et al. 2012). The consensus was set at $60 \%$ which is 6 out of the ten participants votes on the identified compliance practices. The process allowed the grouping of statements that failed to satisfy consensus shown in Section 4.2 and statements that satisfied consensus shown in Section 4.3. The results were examined through the lenses of Compliance and Ethics Group's (OCEG) standards that incorporate compliance as a measure to improve quality and "principled performance" that 
may enhance effectiveness and efficiency practices (Bezzina et al. 2014). The advantage for the Delphi study is clear, as banking experts reach consensus on important considerations discussed in Section 4 that should accompany compliance measures, including emphasis placed on understanding regulatory consultant compliance, maintenance of effective, and independent compliance aligned to organizational objectives.

This article is structured as follows: First, the literature on BHC losses and lack of effect are reviewed. Then, the research methodology, including the sampling strategy, is described. Next, the findings of the impact of important considerations that should accompany compliance measures are presented. Finally, the article concludes with a list of key findings and recommendations.

\section{Literature Review and Conceptual Framework}

The conceptual framework for this e-Delphi study was framed by OCEG's standard that integrates governance, risk management, internal control, assurance, and compliance (GRC capability model) into one functional goal to improve quality and principled performance through measurable tools that may enhance effectiveness and efficiency practices (Bezzina et al. 2014). In several studies, Grant Thornton International argued that the integration of governance, risk management, and compliance can improve effectiveness and efficiency performance (Bezzina et al. 2014). Financial firms' principled performance is achieved through clearly defined goals and values, to meet objectives, identified risks and vulnerabilities with established boundaries, and an effective mechanism for change that enables continuous improvement and performance achievement (Bezzina et al. 2014). Senior bank managers' practices are aligned with goals and values established in goal theory (Chawla 2016) and principal-agent theory (Darayseh and Chazi 2018; Lui 2011). The principal-agent theory discusses the relationship between shareholders (principals) and bank managers (agents; Lui 2011; Darayseh and Chazi 2018) while goal theory has as its focus the role of incentives (Chawla 2016). (Sepdiningtyas and Santoso 2017) addressed the motives and behaviors of managers.

Recent research on principal-agent theory has revealed that risky management behavior arose in the 2008 financial crisis. This financial crisis was a financial innovation weakness that created multiple principal-agent problems, information asymmetry, adverse selection, moral hazard, mortgage fraud, predatory lending, model error with credit rating agencies, managerial slack, and risk shifting (Lui 2011). These significant principal-agent problems resulted in misalignment of party's incentives, excessive leverage and risk-taking linked to the financial crisis, and the issuance of bad loans due to a weak risk management environment cultivated by originators and arrangers (Lui 2011). Applying principal-agent theory to a BHC company setting with senior bank managers provides an understanding of principal-agent theory motivational factors and the behavior of agents in pursuing self-interest while exposing the bank to risk (see Darayseh and Chazi 2018).

In examining the aims of the agent, goal theory highlights the role of incentives and motives Chawla (2016) referred to commission plans which motivate individual to reach the target goal. Similarly, Sepdiningtyas and Santoso (2017) goal theory argued that motivation and incentives are significant to garner commitment to a goal from the individual. Recent research on organizations motivating salespeople using rewards and punishments lead to be disengaged salesperson and poor organizational reputation (Chawla 2016). The concepts of intrinsic and extrinsic motivations reveal that contractual incentives tied to unclear goals established by principals to motivate agents to lead to their dysfunctional behavioral responses (Osterloh and Frey 2000).

\subsection{Integration of Governance, Risk Management, Internal Control, Assurance, and Compliance}

The integration of governance, risk management, internal control, assurance and compliance through macro-prudential regulatory measures enforce supervision and regulation with more robust laws for winding up or resolving too big to fail financial institutions. It requires greater counter-cyclical capital, liquidity, maximum leverage requirements, regulation of executive compensation to reduce moral hazard, reduction of risk, and more regulation of over-the-counter derivatives (Guynn 2010). 


\subsection{Integration of Compliance}

Compliance measure implemented by the Fed requires BHC to conduct two kinds of annual stress tests: A Comprehensive Capital Analysis and Review (CCAR) and Dodd-Frank Asset Stress Tests (DFAST) to prove they meet the capital ratio requirements (Herring 2016). The macroeconomic scenarios are key to the scenario analysis calculation $\mathrm{d}$ in capital adequacy stress test computation (Jacobs 2016). The Fed requires banks to develop their own macroeconomic scenarios, of a statistical model Vector Autoregression (VAR) to exploit the dependency structure between both macroeconomic drivers and modeling segments (Jacobs 2016). Then the Fed independently made their own capital projections computation under each scenario and compared to the bank's capital projection, significant gaps were required to be filled and shortfalls filled by Fed through the Capital Assistance Program (CAP). The Basel Committee has proposed hundreds of pages of new regulations and supervisory practices, none of which are aimed at simplifying the regulatory stress test system. Instead, the system has become markedly more complicated (Herring 2016).

As part of assurance and compliance measures, banks are required to have model validation teams different from model risk managers. Model risk management teams should develop and sound models, governance and control mechanisms such as board and senior management oversight, policies and procedures, controls and compliance, and an appropriate incentive and organizational structure (Goldberg 2017). Model risk managers spend a significant amount of time talking with the risk-takers (Goldberg 2017). Models should accurately project as regulators impose penalties on those banks that hold too little capital (Abou-El-Sood 2017). Regulators capital stress testing and of models to project revenue, income/losses, balance sheet assets and liabilities, and regulatory capital ratios (Allen et al. 2016).

Although stress test is a full compliance activity, it can be complex, often onerous and pull bank executives away from mission-critical business objectives, instead of thrusting them into months of data compilation, and potentially tense meetings with regulators (Lee 2015). The accuracy of these stress test measures is being questioned whether they pose a significant danger to the financial sector stability because of lack of capability to predict actual market risk and losses. The reliance on historical data and events, and the test of the static balance sheet can be a weakness (Baradaran 2014). This factor coupled with the Fed capital compliance demands without thinking about banks maintaining profitability or international competitiveness is a burden for banks (Fahey 2016).

The Fed stress test of banks in 2015 found Bank of America required to raise new capital and resubmit its plans, Bank of America spent \$100 million to develop its 2015 resubmission, Citigroup spent \$180 million in the second half of 2014 to prepare its 2014 submission, Morgan Stanley was required to submit a revised capital plan for 2016, Deutsche Bank and Santander US failed the tests and prohibited from paying dividends and stock buybacks (Walker et al. 2017). The efforts toward enhanced risk management stronger reliance on capital, and better liquidity management continuously fall short of its goals to cure bank risk of default (Handorf 2017).

\section{Research Methodology}

The e-Delphi method allows an exploration of an area of future thinking that goes beyond the currently known or believed (Hsu and Sandford 2007). Data is collected in a naturalistic manner through the interview, surveys, questionnaires that ask "how", "why", and "what" questions that are open-ended in nature (Gaus 2017). The potential of the e-Delphi technique is in its consensus-building process that has three rounds of questionnaires to gather opinions from banking finance experts across the United States.

To perform this e-Delphi study, 10 finance experts who are: employed a minimum of 10 years in banking, possessed an MBA in Finance, and, currently employed as a consultant to a large bank in the U.S. are identified to form a panel of experts. Participants were recruited via social media (LinkedIn groups) and an initial survey consists of five questions was submitted with subsequent follow-up rounds. The individuals were elected as part of a panel of expert participants because of their 
background and knowledge on the subject. Data were collected from three electronic questionnaires submitted through Qualtrics. The questionnaire was developed by the researcher from the literature and what is known about the topic (Brady 2015) corresponding to each Compliance and Ethics Group's standard concept (compliance) and overarching research question (Bezzina et al. 2014).

The study data and theoretical triangulation practice increase confidence in research data, reveal unique findings, integrate theories, and understand the problem (Thurmond 2001). Data triangulation gathered multiple sources of the survey collected at different times, gather and compared them. Questionnaires obtained a more comprehensive view of expert views and strengthen the qualitative fieldwork (Thurmond 2001). Theoretical triangulation facilitated more than one theoretical position to interpret data. The study was conducted with multiple lenses and questions that lend support to the findings (Thurmond 2001). This study compared the panelist responses to existing research and identify factors that are known in the existing literature that further establish validity. Debriefing and member checking strategy obtained credibility. Participants were provided with the opportunity to review and comment on the collected data (Stewart et al. 2017). The audit trail attained dependability and confirmability (Kemparaj and Chavan 2013). Thick description enabled the detail documentation of the study, which allows the reader to evaluate the conclusions drawn and its transferability to other settings, situations and people (Viloria 2018).

\subsection{Sample}

The purpose of the study and the open-ended nature of the research question supported the Delphi design. The email invitations were sent to potential participants and a link to an expert screening e-survey administered using Qualtrics (Cole et al. 2013). This e-Delphi method combined expert opinions to arrive at an informed group consensus on a complex problem (Davidson 2013; Guzys et al. 2015). Experts across the United States and purposive sampling were employed to solicit 10 experts to form a panel with experience in the underlining study constructs. Participants were recruited via social media (LinkedIn groups) and an initial survey consists of five questions was submitted with subsequent follow-up rounds.

The individuals were elected as part of a panel of expert participants because of their background and knowledge on the subject. The inclusion criteria for participation in this e-Delphi study as a panelist was as follows: (1) adult over the age of 18, (2) employed a minimum of 10 years in the banking industry, (3) possession of an MBA in Finance, and, (4) currently employed as a consultant to a large bank in the United States. These criteria were aligned with guidelines for expert judgment in model-based economic evaluations (Iglesias et al. 2016). As noted by (Peterson 2018), there is no set of universal guidelines for qualifying an expert for a Delphi panel.

\subsection{Data Collection}

The e-Delphi design collected critical data electronically through the process of surveys that ask "how", "why", and "what" questions that are open-ended in nature (Gaus 2017). The three data collection instruments consisted of electronic questionnaires. The study incorporated the recommended three rounds of questionnaires, first-round questionnaire s open-ended approach to gathering expert opinions on a certain issue, the second questionnaire asks the panel of experts to rank these statements, and third, the group reach consensus (Cole et al. 2013; Donohoe et al. 2012). Delphi use three rounds to answer a research question (Linstone and Turoff 2011).

In the first round, the questionnaire required experts to list and briefly describe at least five responses to the questions (see Hirschhorn 2019; Okoli and Pawlowski 2004). In the second round, the panelist was provided the questionnaire developed based on the answers from Round 1 (a generated aggregated list of statements based on Round 1 questions) (see Okoli and Pawlowski 2004). Experts were asked to shortlist responses on the listed inventories produced based on the relevance and ability to provide insights on the most critical aspects of research questions (Hirschhorn 2019). In Round 3, the panelist received the questionnaire generated with the Round 2's responses. Experts were asked to rate 
each statement on the second-round questionnaire against two separate (desirability and feasibility) 5-point Likert scales.

\subsection{Data Analysis}

Data analysis represented a critical component of this e-Delphi study. The expert responses to open-ended questions were qualitatively analyzed, coded, major themes identified, and the information identified contributed to the study findings (Hirschhorn 2019). The iterative 3-round e-Delphi approach led to a large amount of data to analyze. The tools provided by Qualtrics and Microsoft Excel made it feasible for quick data analysis. The data derived from the question was coded and then linked the themes to classification grounded in the conceptual framework and the literature.

The key phrases from the Round 1 responses were highlighted that answered each research question, pattern coded to collect similar coded statements (see Saldaña 2016). The application of content analysis identified themes, patterns, indexing, and categories, with nonrecurring evidence associated with individual cases (Saldaña 2016). In Round 2, an inventory list was sent to the panelists (see Hirschhorn 2019). The panelists were asked to vote on the inventory list and a shortlist generated based on majority votes. The vote for each statement on the second-round questionnaire against two separate (desirability and feasibility) 5-point Likert scales. Desirability measures ranged from (1) highly undesirable to (5) highly desirable, and feasibility ranged from (1) definitely infeasible to (5) definitely. In Round 3, experts were asked in this rating process to consider the elements shortlisted in Round 2 and to rate each statement on the second-round questionnaire against two separate (desirability and feasibility) 5-point Likert scales. The data analysis revealed a consensus on seven compliance activities constituting a senior manager's effective practice towards capital regulation in BHCs.

\section{Results}

4.1. Research Question: Describe Compliance Practices Senior Bank Managers Can Implement towards Capital Regulation that Can Be Effective in Reducing Losses in Bank Holding Companies

The panelists' recommendations for compliance practices in the first-round questionnaire generated 23 statements that can be effective in reducing losses in BHCs. These 23 statements were provided to the panelist in Round 2 for the panelist to vote for each statement against two separate (desirability and feasibility) 5-point Likert scales. Desirability measures ranged from (1) highly undesirable to (5) highly desirable, and feasibility ranged from (1) definitely infeasible to (5) definitely feasible. The results of the voting in Round 2 generated 15 statements that were $d$ to construct the Round 3 questionnaire. The panelist was asked to vote in this final round on the 15 statements based on 5-point Likert scales. Statements that received 6 out of 10 votes met the consensus threshold of $60 \%$. The compliance statements were grouped in the following subcategories: compliance, reporting, technology, ethics, training, liquidity risk, partnership. Nonconsensus and final consensus both highlight the areas for banks to consider when addressing the central problem of this study. Table 1 contains the number of statements in each rounds and the overall study findings. Table 2 contains data corresponding to the voting results from each round of the study.

Table 1. Overall Study Findings.

\begin{tabular}{cccccc}
\hline Category & $\begin{array}{c}\text { Round 1 } \\
\text { Generated } \\
\text { Statements }\end{array}$ & $\begin{array}{c}\text { Round 2 } \\
\text { Statements }\end{array}$ & $\begin{array}{c}\text { Round 3 } \\
\text { Statements }\end{array}$ & $\begin{array}{c}\text { Consensus } \\
\text { Statements }\end{array}$ & $\begin{array}{c}\text { Portion of Statements } \\
\text { Representing } \\
\text { Consensus }\end{array}$ \\
\hline $\begin{array}{c}\text { Compliance } \\
\text { Practices }\end{array}$ & 23 & 23 & 15 & 7 & $21 \%$ \\
\hline
\end{tabular}


Table 2. Statements Failing to Meet Consensus Threshold in Round 3.

\begin{tabular}{|c|c|c|}
\hline Statement & Rating (Desirability) & Rating (Feasibility) \\
\hline $\begin{array}{l}\text { Compliance practices towards capital regulation that can } \\
\text { be effective in reducing losses include tests that measure } \\
\text { compliance with regulatory requirements. }\end{array}$ & 4 & 5 \\
\hline $\begin{array}{c}\text { Compliance practices towards capital regulation that can } \\
\text { be effective in reducing losses include establishing and } \\
\text { communicating compliance policy across } \\
\text { pertinent organizations. }\end{array}$ & 5 & 7 \\
\hline $\begin{array}{c}\text { Compliance practices towards capital regulation that can } \\
\text { be effective in reducing losses include identification of } \\
\text { compliance risks and controls at the relevant } \\
\text { organizational level. }\end{array}$ & 5 & 6 \\
\hline $\begin{array}{c}\text { Compliance practices towards capital regulation that can } \\
\text { be effective in reducing losses include ensuring } \\
\text { compliance function is adhered to with clarity of } \\
\text { responsibilities and remediation steps for breaches } \\
\text { are discovered. }\end{array}$ & 5 & 5 \\
\hline $\begin{array}{c}\text { Compliance practices towards capital regulation that can } \\
\text { be effective in reducing losses include a periodic } \\
\text { assessment of issues and issues closures. }\end{array}$ & 5 & 5 \\
\hline $\begin{array}{l}\text { Compliance practices towards capital regulation that can } \\
\text { be effective in reducing losses include reporting of } \\
\text { compliance to upper management so they can make } \\
\text { informed decisions on compliance risks. }\end{array}$ & 4 & 5 \\
\hline $\begin{array}{c}\text { Compliance practices towards capital regulation that can } \\
\text { be effective in reducing losses include internal controls } \\
\text { utilized at every level to ensure potential liabilities } \\
\text { are eliminated. }\end{array}$ & 4 & 3 \\
\hline $\begin{array}{l}\text { Compliance practices towards capital regulation that can } \\
\text { be effective in reducing losses include ongoing training } \\
\text { of all stakeholders relative to compliance rules and } \\
\text { regulations including BSA teams, branch control teams, } \\
\text { and cybersecurity teams. }\end{array}$ & 5 & 4 \\
\hline
\end{tabular}

The panelists made references collectively in Round 1 and Round 2 to risk identification, communication, and responsibilities as effective practices that can be $\mathrm{d}$ to recognize a senior manager's effective practice towards capital regulation in bank holding companies. However, statements with these concepts did not make the Round 3 consensus level of 6 out 10 votes on desirability and feasibility of these statements. Of the 15 statements voted on in Round 3, eight statements did not satisfy the consensus threshold and seven statements met the consensus threshold in Round 3. Table 2 displays the eight statements that failed to satisfy the consensus threshold, while Table 3 displays statements that satisfy the consensus threshold in Round 3. 
Table 3. Statements that Satisfied Consensus Threshold in Round 3.

\begin{tabular}{ccc}
\hline \multicolumn{1}{c}{ Statement } & Rating (Desirability) & Rating (Feasibility) \\
\hline $\begin{array}{c}\text { Compliance practices towards capital regulation that can } \\
\text { be effective in reducing losses include maintenance of } \\
\text { effective and independent compliance consistent with } \\
\text { the organizational objectives. }\end{array}$ & 6 & 6 \\
\hline $\begin{array}{c}\text { Compliance practices towards capital regulation that can } \\
\text { be effective in reducing losses include a clear definition } \\
\text { of data source for compliance analytics. }\end{array}$ & 4 \\
\hline $\begin{array}{c}\text { Compliance practices towards capital regulation that can } \\
\text { be effective in reducing losses include ensuring } \\
\text { to upper management. }\end{array}$ & 6 \\
\hline $\begin{array}{c}\text { Compliance practices towards capital regulation that can } \\
\text { be effective in reducing losses include top leadership } \\
\text { must be a champion of the code of ethics. }\end{array}$ & 7 \\
\hline $\begin{array}{c}\text { Compliance practices towards capital regulation that can } \\
\text { be effective in reducing losses include strong morals } \\
\text { and integrity. }\end{array}$ & 6 \\
\hline $\begin{array}{c}\text { Compliance practices towards capital regulation that can } \\
\text { be effective in reducing losses include the right products } \\
\text { for clients. }\end{array}$ & 6 \\
\hline $\begin{array}{c}\text { Compliance practices towards capital regulation that can } \\
\text { be effective in reducing losses include understanding } \\
\text { regulatory compliance }\end{array}$ & 6 \\
\hline
\end{tabular}

\subsection{Statements that Failed to Satisfy Consensus Threshold}

Compliance statements that did not satisfy the consensus level of at least 6 of the 10 votes in Round 3 were identified as nonconsensus statements. As indicated in Table 2, eight statements failed to meet the consensus threshold in Round 3.

Compliance statement that refers to the stress test failed to pass to Round 3 and this supports the existing literature. This is evidenced by (Denev and Mutnikas 2016), (Dowd and Hutchinson 2016), and (Herring 2016) regarding stress testing of capital through federal regulators risk models has been ineffective and costly. It requires a significant amount of human and monetary resources. This is reflective of doubts by the panel in their unfavorable rating of stress testing, and loss- and resource-estimation methodologies. In contrast, this finding diverges from the assertion by (Kolari and Ivan 2017) that Basel standards over tress tests are some recommended measures for banks. (Ong and Pazarbasioglu 2014) asserted stress tests must be rigorous in the scope of coverage and scenario design so that the results capture the actual health of the bank. This finding supports the assertions of Herring (2016) and Lee (2015) although stress test is a full compliance activity, it can be complex, often onerous and pull bank executives away from mission-critical business objectives, instead thrust them into months of data compilation. Basel Committee has proposed hundreds of pages of new regulations and supervisory practices, none of which are aimed at simplifying the regulatory stress test system.

The comments and ratings highlight an assortment of viewpoints toward the issue of stress test playing a role in capital structure and risk appetite. This is an accurate depiction of the issue depicted by Kapinos and Mitnik (2016) regarding capital regulation law that does not identify acceptable ways to conduct the stress tests of capital. Other statements by the panelist in Round 2 questioned whether stress testing put forth by bank regulators might be effective, which was reflective in their ratings. The implication is that members of the panel see regulatory stress tests and its's efforts in the capital structure as doubtful exercises that can be effective measures in the bank. 
Despite compliance analytics having statements that made it to Round 3, the majority of the statements centered around compliance metrics failed to meet the $60 \%$ consensus threshold. The failure of these statements to pass to Round 3 supports the skepticism evidenced by Goldberg (2017) that assurance and compliance measures require banks to have model validation teams different from model risk managers to develop models, controls and compliance (Goldberg 2017). This is reflective of doubts by the panel in their unfavorable rating of periodic assessment of compliance adherence with metrics. These statements were among the 32 statements that had a feasibility score that was not greater than the mean score of 2 to pass to Round 3. In contrast, this finding diverges from the assertion of Nitescu and Duna (2016) that effective management of risk relates to capital and financial system compliance at the systemic level. The comments and ratings highlight an assortment of viewpoints toward the issue of compliance analytics. Other statements by the panelist in Round 2 questioned whether compliance is more of a backward-looking art than a forward-looking science of the bank. The implication is that members of the panel see compliance metrics as doubtful exercises that can be effective measures in the bank.

Scenarios statements centered around compliance tools, standards and metrics (scorecard/dashboard), scenarios, indicators and bank regulation failed to meet the $60 \%$ consensus threshold. The failure of these statements to pass to Round 3 supports the skepticism evidenced by Bellof and Wehn (2018), and Crabb (2018) that scenarios lack transparency and there are areas of model risk that requires further investigation: estimation errors or parameter uncertainties cad by algorithmic methods of statistics, computational estimators $\mathrm{d}$ in the model framework, individual model assumptions variations $\mathrm{d}$ in the algorithm, challenger * models replaced by alternative model algorithm assumptions which drives the assessment of model risk. This is reflective of doubts by the panel in their unfavorable rating of scenario tools available to ensure that capital regulation is managed to within guidelines.

In contrast, this finding diverges from the assertion by Lee (2015) that linking of scenarios and stress-testing processes can capture the bank's material exposures, activities, and employing multiple conceptually sound activities and approaches. The third-party risk assessment and modeling tools can greatly assist with compliance and risk (Lee 2015). This finding supports the assertions of difficulty in financial tools such as models $d$ to analyze the relationship between the financial conditions of financial intermediaries and the business cycle (Fukuda 2016).

The comments and ratings highlight an assortment of viewpoints toward the issue of tools available to ensure that capital regulation is managed within the guidelines of the financial environment. Other statements by the panelist in Round 2 questioned whether adhering to standard banking regulations such as bank secrecy acts, Reg CC, and D might be effective. The implication is that members of the panel see scenarios, indicators and bank regulation as doubtful exercises that can be effective measures in the bank.

\subsection{Statements that Satisfied the Consensus Threshold}

Compliance statements that had at least 6 of the 10 votes a $60 \%$ consensus in Round 3 were identified as consensus statements. These statements represented a consensus by the panel on how to recognize a senior manager's effective compliance practice towards capital regulation in bank holding companies. As indicated in Table 3, seven statements had at least 6 of the 10 votes a $60 \%$ consensus in Round 3.

Compliance analytics, alignment with organizational objectives, and understanding regulatory compliance received high ratings from the panelist in Round 3. This indicated high levels of desirability and feasibility of regulatory compliance practices. This lends support to the importance placed on having compliance measures in place as demonstrated in the assertion of Boora (2018) that compliance guidance recommended that banks should develop effective strategies and policies to comply with capital adequacy requirements of Basel III. It is mandatory for banks to become Basel-compliant. The findings extend Boora (2018) work by drawing attention to important considerations that should accompany compliance measures, including (a) emphasis placed on understanding regulatory 
compliance, (b) maintenance of effective and independent compliance align to organizational objectives, (c) clear definition of data source for compliance analytics.

The considerations alluded to the emphasis being placed on meeting compliance requirements through understanding regulatory compliance, independently align compliance goals to business objectives, and clearly defined compliance analytic tools to measure the effectiveness of these compliance initiatives. As noted by Goldberg (2017), banks are required to controls and compliance measurements in place as part of their organizational structure (Goldberg 2017).

Top leadership must be a champion of code of Ethics, exhibit strong morals and integrity, right products are matched to customers, and timely reporting of activities to upper management received consensus level ratings from the panelist in Round 3. This indicated high levels of desirability and feasibility towards leadership champion of code of ethics and strong morals and integrity. These statements had 6 votes or more to meet the $60 \%$ consensus threshold in Round 3 . This lends support to the assertions of Tourigny et al. (2003) that the lack of exhibited behavior reflecting principles of governance and ethical standards can ca bank failures. Noreen et al. (2016) concluded that regulatory authorities must work on the ways to control the moral hazard behavior of banks. The findings extend Noreen et al. (2016), and Tourigny et al. (2003) work by drawing attention to two important considerations that should accompany ethics in bank, including (a) the right products for clients, and (b) leadership champion of code of ethics, and strong morals and integrity.

The considerations allude to having leadership being champion of morals and integrity will display ethical behavior reflecting in their product choices for their clients. As noted by Lui (2011) when bank managers lack morals and ethics this is displayed in them pursue their own financial and gains while exposing shareholders to significant losses from their risky investments.

\section{Conclusions}

Compliance measures emphasized in the Dodd-Frank Bill 2010, Section 165 arise as a response to the 2008 financial crisis. Large banks are required to adhere to the maintenance of sufficient capital to cover their losses. The continuance of unanticipated losses in megabanks, failure to meet the capital ratio of $8 \%$, and the ineffective delivery of compliance measures in capital regulation has motivated the interest of this e-Delphi study towards the identification of effective compliance practice that can be implemented in BHCs. To do this, an e-Delphi study is employed to build consensus among 10 banking finance experts across the United States on how to identify effective compliance practices towards capital regulation in banks that can reduce significant losses and risk management behavior. As a result, our conclusion may add knowledge on important considerations that should accompany compliance measures and extends concepts in OCEG standards that implement compliance as a measure to improve quality and performance.

The review of statements that are identified as nonconsensus and consensus both highlight the areas for banks to consider when addressing the central problem of compliance measures in BHCs. The consensus statements identified compliance activities that can be effective in BHC while nonconsensus are deemed unfavorable by the panelist as effective towards capital regulation. Eight statements did not satisfy the consensus threshold while seven statements met the consensus threshold that identifies considerations that should accompany compliance measures to achieve effectiveness in BHCs.

Compliance policies and risk controls, periodic assessment of issues, remediation steps for responsibilities breaches that supports the annual stress test process were voted as nonconsensus statements. Statements that refer to stress test is reflective of doubts by the panel in their unfavorable ratings. Although stress test is a compliance activity, it can be complex, often onerous and pull bank executives away from mission-critical business objectives. Basel Committee has proposed hundreds of pages of new regulations and supervisory practices, none of which are aimed at simplifying the regulatory stress test system.

Scenarios statements centered around compliance tools, standards and metrics (scorecard/dashboard), indicators and bank regulation were deemed unfavorable by the panelists and were identified as 
nonconsensus statements. This skepticism displayed by the panel of exerting is corroborated by the existing literature that scenarios lack transparency and there are areas of model risk that require further investigation. This is evident in the estimation errors or parameter uncertainties caused by algorithmic methods. As such, there are difficulties in financial tools used to analyze the relationship between the financial conditions of intermediaries and the business cycle.

Consensus statements that could be effective practice refer to compliance analytics, alignment with organizational objectives, and understanding regulatory compliance. These statements received high ratings from the panelist. The panel highlighted the importance of having compliance measures in place including (a) emphasis placed on understanding regulatory compliance, (b) maintenance of effective and independent compliance align to organizational objectives, (c) clear definition of data source for compliance analytics. Top leadership as a champion of code of Ethics, exhibit strong morals and integrity, right products matched to customers, and timely reporting of activities to upper management was voted by the panel as activities that can be effective in BHCs. These consensus compliance statements can influence positive bank activities through reducing senior manager's investment in high-risk products and more selection of conservative investments. Heightened ethical awareness cause bank managers choices to thereby reduce fraudulent behaviors, decreasing business losses stemming from errors and fraud. The lack of exhibited behavior reflecting principles of governance and ethical standards can cause bank failures.

The relevance of identifying seven consensus compliance statements can be effective towards the capital regulation reduction of significant losses, and risky management behavior in banks. The results of this study may be used by bank practitioners and the Federal Reserve Bank (Fed) to construct action plans, policies and desktop procedures, and training programs that may lead to a reduction in risk management behaviors. These collaborative practices can inform positive bank activities and decrease business losses stemming from errors and fraud.

\section{Recommendations for Future Research}

Scholars may conduct further studies to compare and contrast the results of this E-Delphi study in many ways. This study did not confine the experts in banking to a specific region in the United States, scholars may desire to conduct further studies on this central research topic using different delimitations based on this dimension. One boundary included the decision to focus the overall research question on effective senior managers' compliance practices towards capital regulation. The decision to develop a conceptual framework based on OCEG standards that integrates governance, risk management, internal control, assurance and compliance (GRC capability model), principal-agent theory, and goal theory and the use of the Delphi method is another delimitation. In light of the need for risk mitigation framework that incorporate model risk measures that identifies economically dangerous uncertainties and their risk factors, quantitative assessment and risk measurement approach to risk embedded in financial decision-making, portfolio and investment planning and the respective management activities (Baker and Filbeck 2015), researchers may want to conduct similar Delphi studies to a specific region in the United States.

Due to the potential difference in the functionality of banks in different states and geographic regions within the United States, Delphi studies on this topic localized to a specific region may present a viable option for future research. Future scholars may want to use a varied panelist criterion from the one used in this study. As the eligibility criteria for this study confined panelist to individuals: (1) adult over the age of 18, (2) employed a minimum of 10 years in the banking industry, (3) possession of an MBA in Finance, and, (4) currently employed as a consultant to a large bank in the United States. Scholars may modify panel eligibility criteria to include industry-specific experience and prior professional and academic publications. Scholars may also wish to conduct Delphi studies with panels comprised entirely of senior managers to examine their behavior on the study topic. The results of future studies may provide invaluable points of comparison with the results of the present study. Scholars may stand in a position to develop a further study based on these Delphi findings. 
Author Contributions: Conceptualization, S.V.; Methodology, S.V.; Software, S.V.; Validation, S.V.; Formal analysis, S.V.; Investigation, S.V.; Resources, S.V.; Data curation, S.V.; Writing-original draft preparation, S.V.; Writing-review M.N. and D.H; Editing, S.V.; Visualization, S.V.; Supervision, M.N. and D.H.; Project administration, S.V. All authors have read and agreed to the published version of the manuscript.

Funding: This research received no external funding.

Conflicts of Interest: The authors declare no conflict of interest.

\section{References}

Abou-El-Sood, Heba. 2017. Corporate governance structure and capital adequacy: Implications to bank risk taking. International Journal of Managerial Finance 13: 165-85. [CrossRef]

Allen, Franklin, Itay Goldstein, Julapa Jagtiani, and William W. Lang. 2016. Enhancing prudential standards in financial regulations. Journal of Financial Services Research 49: 133-49. [CrossRef]

Baker, H. Kent, and Greg Filbeck. 2015. Risk management: A panel discussion. Journal of Applied Finance 25: 46-57.

Baradaran, Mehrsa. 2014. Regulation by hypothetical. Vanderbilt Law Review 67: 1247-326. Available online: https://www.vanderbiltlawreview.org/ (accessed on 12 June 2019).

Barr, Michael S. 2017. Financial reform: Making the system safer and fairer. RSF: The Russell Sage Foundation. Journal of the Social Sciences 3: 2-18. [CrossRef]

Bellof, Tilo, and Carsten S. Wehn. 2018. On the treatment of model risk in the internal capital dequacy assessment process. Journal of Applied Finance and Banking 8: 1-15. Available online: http://www.scienpress.com/journal_ focus.asp?Main_Id=56 (accessed on 12 June 2019).

Berger, Allen N., Filippo Curti, Atanas Mihov, and John Sedunov. 2018. Operational risk is more systemic than you think: Evidence from US bank holding companies. Avail. SSRN 3210808. [CrossRef]

Bezzina, Frank, Simon Grima, and Josephine Mamo. 2014. Risk management practices adopted by financial firms in Malta. Managerial Finance 40: 587-612. [CrossRef]

Boora, Krishan K. 2018. Implementation of basel III norms in banking industry: A review of empirical literature. IUP Journal of Bank Management 17: 7-24. Available online: https://econpapers.repec.org/article/icficfjbm/ (accessed on 12 June 2019).

Brady, Shane R. 2015. Utilizing and adapting the Delphi method for use in qualitative research. International Journal of Qualitative Methods 14: 1-6. [CrossRef]

Chawla, Vaibhav. 2016. Workplace spirituality governance: Impact on customer orientation and salesperson performance. The Journal of Business $\mathcal{E}$ Industrial Marketing 31: 498-506. [CrossRef]

Cole, Zachary Douglas, Holly M. Donohoe, and Michael L. Stellefson. 2013. Internet-based Delphi research: Case based discussion. Environmental management 51: 511-23. [CrossRef]

Crabb, John. 2018. CCAR results highlight Fed's lack of transparency. International Financial Law Review. Available online: https://www.iflr.com/ (accessed on 12 June 2019).

Crawford, John. 2017. Lesson unlearned?: Regulatory reform and financial stability in the Trump Administration. Columbia Law Review Online. forthcoming; UC Hastings Research Paper No. 242. Available online: https: //columbialawreview.org/ (accessed on 12 June 2019).

Dandapani, Krishnan, Edward R. Lawrence, and Fernando M. Patterson. 2017. The effect of holding company affiliation on bank risk and the 2008 financial crisis. Studies in Economics and Finance 34: 105-21. [CrossRef]

Darayseh, Musa, and Abdelaziz Chazi. 2018. Bank specifics, economics environment, and agency theory: Determinants of banking performance in GCC. The Journal of Developing Areas 52: 199-212. [CrossRef]

Davidson, Phillip L. 2013. The Delphi technique in doctoral research: Considerations and rationale. Review of Higher Education and Self-Learning 6: 53-65. Available online: www.intellectbase.org/journals (accessed on 12 June 2019).

Denev, Alexander, and Yaacov Mutnikas. 2016. A formalized, integrated and visual approach to stress testing. Risk Management 18: 189-216. [CrossRef]

Donohoe, Holly, Michael Stellefson, and Bethany Tennant. 2012. Advantages and limitations of the e- Delphi technique: Implications for health education researchers. American Journal of Health Education 43: 38-46. [CrossRef]

Dowd, Kevin, and Martin Hutchinson. 2016. Learning the right lessons from the financial crisis. Cato Journal 36: 393-413. Available online: https://www.cato.org/ (accessed on 12 June 2019). 
Eastburn, Ronald William, and Alex Sharland. 2017. Risk management and managerial mindset. The Journal of Risk Finance 18: 21-47. [CrossRef]

Fahey, Caitlin. 2016. Are We Ready for the Next Financial Crisis? Fordham Journal of Corporate E Financial Law 21: 232-94. Available online: https://ir.lawnet.fordham.edu/jcfl/ (accessed on 12 June 2019).

Fukuda, Shin. 2016. Bank's capital requirements in the business cycle: A DSGE analysis with a news shock. Journal of Applied Finance and Banking 6: 115-28. Available online: http://www.scienpress.com/journal_focus. asp?Main_Id=56 (accessed on 12 June 2019).

Gaus, Nurdiana. 2017. Selecting research approaches and research designs: A reflective essay. Qualitative Research Journal 17: 99-112. [CrossRef]

Goldberg, Martin. 2017. Much of model risk does not come from any model. Journal of Structured Finance 23: 32-37. [CrossRef]

Gong, Di, Harry Huizinga, and Luc Laeven. 2018. Nonconsolidated affiliates, bank capitalization, and risk taking. Journal of Banking \& Finance 97: 109-29. [CrossRef]

Guynn, Randall D. 2010. The global financial crisis and proposed regulatory reform. Brigham Young University Law Review 2010: 421-513. Available online: https://digitalcommons.law.byu.edu/lawreview/ (accessed on 12 June 2019).

Guzys, Diana, Virginia Dickson-Swift, Amanda Kenny, and Guinever Threlkeld. 2015. Gadamerian philosophical hermeneutics as a useful methodological framework for the Delphi technique. International Journal of Qualitative Studies on Health and Well-being 10: 26291. [CrossRef]

Handorf, William C. 2017. Regulatory ratios, CDS spreads, and credit ratings in a favorable economic environment. Journal of Banking Regulation 18: 268-85. [CrossRef]

Herring, Richard J. 2016. Less really can be more: Why simplicity \& comparability should be regulatory objectives. Atlantic Economic Journal 44: 33-50. [CrossRef]

Hirschhorn, Fabio. 2019. Reflections on the application of the Delphi method: Lessons from a case in public transport research. International Journal of Social Research Methodology 22: 309-22. [CrossRef]

Hsu, Chia-Chien, and Brian A. Sandford. 2007. The Delphi technique: Making sense of consensus. Practical Assessment, Research \& Evaluation 12: 1-8. Available online: https://www.pareonline.net/ (accessed on 12 June 2019).

Ibiyemi, Abayomi O., Mohd Adnan Yasmin, and Nasir Daud Md. 2016. The validity of the classical delphi applications for assessing the industrial sustainability-correction factor: An example study. Foresight: The Journal of Futures Studies, Strategic Thinking and Policy 18: 603-24. [CrossRef]

Iglesias, C. P., A. Thompson, W. H. Rogowski, and K. Payne. 2016. Reporting guidelines for the use of expert judgement in model-based economic evaluations. PharmacoEconomics 34: 1161-72. [CrossRef] [PubMed]

Jacobs, Michael. 2016. Stress testing and a comparison of alternative methodologies for scenario generation. Journal of Applied Finance and Banking 6: 123-56. Available online: http://www.scienpress.com/journal_focus. asp?Main_Id=56 (accessed on 12 June 2019).

Kapinos, Pavel, and Oscar A. Mitnik. 2016. A top-down approach to stress-testing banks. Journal of Financial Services Research 49: 229-64. [CrossRef]

Kemparaj, Umesh, and Sangeeta Chavan. 2013. Qualitative research: A brief description. Indian Journal of Medical Sciences 67: 89-98. [CrossRef]

Kolari, James W., and Pastor Sanz Ivan. 2017. Systemic risk measurement in banking using self-organizing maps. Journal of Banking Regulation 18: 338-58. [CrossRef]

Lee, Larry. 2015. Successfully navigating CCAR and DFAST. Journal of Structured Finance 21: 51-55. [CrossRef]

Linstone, Harold. A., and Murray Turoff. 2011. Delphi: A brief look backward and forward. Technological Forecasting and Social Change 78: 1712-19. [CrossRef]

Lui, Alison. 2011. Multiple principal-agent problems in securitisation. The Poznan University of Economics Review 11: 47-72. Available online: http://www.ebr.edu.pl/ (accessed on 12 June 2019).

Nitescu, Dan Costin, and Florin Alexandru Duna. 2016. Liquidity management and the banking lending mechanism. Revista De Management Comparat International 17: 403-13. Available online: https://www.ceeol. com/search/journal-detail?id=2201 (accessed on 12 June 2019).

Noreen, Umara, Fizza Alamdar, and Tabassum Tariq. 2016. Capital buffers and bank risk: Empirical study of adjustment of pakistani banks. International Journal of Economics and Financial Issues 6. Available online: https://www.econjournals.com/ (accessed on 12 June 2019). 
Okoli, Chitu, and Suzanne D. Pawlowski. 2004. The Delphi method as a research tool: An example, design considerations and applications. Information \& Management 42: 15-29. [CrossRef]

Ong, Li Lian, and Ceyla Pazarbasioglu. 2014. Credibility and crisis stress testing. International Journal of Financial Studies 2: 15-81. [CrossRef]

Osterloh, Margit, and Bruno S. Frey. 2000. Motivation, knowledge transfer, and organizational forms. Organization Science 11: 538-50. [CrossRef]

Peterson, Evan. 2018. Techniques for addressing managerial attitudes towards lawyers and the law. Law Journal 28: $1-25$.

Rahman, K. Sabeel. 2012. Democracy and productivity: The glass-steagall act and the shifting discourse of financial regulation. Journal of Policy History: JPH 24: 612-43. [CrossRef]

Saldaña, Johnny. 2016. The Coding Manual for Qualitative Researchers, 3rd ed. Thousand Oaks: Sage Publications.

Sarin, Natasha, and Lawrence H. Summers. 2016. Understanding bank risk through market measures. Brookings Papers on Economic Activity, 57-127. [CrossRef]

Sepdiningtyas, Restu, and Claudius Budi Santoso. 2017. The influence of leader-member exchange on individual performance: The roles of work engagement as a mediating variable and co-workers support as a moderating variable. Review of Integrative Business and Economics Research 6: 285-305. Available online: http://buscompress. com/journal-home.html (accessed on 12 June 2019).

Stewart, Heather, Rod Gapp, and Ian Harwood. 2017. Exploring the alchemy of qualitative management research: Seeking trustworthiness, credibility and rigor through crystallization. The Qualitative Report 22: 1-19.

Tanda, Alessandra. 2015. The effects of bank regulation on the relationship between capital and risk. Comparative Economic Studies 57: 31-54. [CrossRef]

Thurmond, Veronica A. 2001. The point of triangulation. Journal of Nursing Scholarship 33: 253-58. [CrossRef]

Tourigny, Louise, William L. Dougan, John Washbush, and Christine Clements. 2003. Explaining executive integrity: Governance, charisma, personality and agency. Management Decision 41: 1035-49. [CrossRef]

Viloria, Dominick D. 2018. Exploring a socially-constructed concept and precursors of employee engagement in the Philippine setting. Review of Integrative Business and Economics Research 7: 1-25. Available online: http://buscompress.com/journal-home.html (accessed on 12 June 2019).

Walker, David A., Elizabeth Dammeyer, and Erica Lee. 2017. Banks' dodd-frank costs vs. earnings on reserves. Journal of Accounting and Finance 17: 10-28. [CrossRef]

Wan, Joshua S. 2016. Systematically important asset managers: Perspectives on dodd-frank's systemic designation mechanism. Columbia Law Review 116: 805-41. Available online: https://columbialawreview.org/ (accessed on 12 June 2019).

Yeoh, Peter. 2016. Corporate governance failures and the road to crime. Journal of Financial Crime 23: 216-30. [CrossRef]

(C) 2020 by the authors. Licensee MDPI, Basel, Switzerland. This article is an open access article distributed under the terms and conditions of the Creative Commons Attribution (CC BY) license (http://creativecommons.org/licenses/by/4.0/). 